\title{
Peach Rusty Spot Epidemics: Temporal Analysis and Relationship to Fruit Growth
}

\author{
Laura A. Furman and Norman Lalancette, Rutgers University, Agricultural Research and Extension Center, \\ Bridgeton, NJ 08302-5919; and James F. White, Jr., Rutgers University, Cook College, Department of Plant Biol- \\ ogy and Pathology, New Brunswick, NJ 08901-8520
}

\begin{abstract}
Furman, L. A., Lalancette, N., and White, J. F., Jr. 2003. Peach rusty spot epidemics: Temporal analysis and relationship to fruit growth. Plant Dis. 87:366-374.

Incidence and severity of peach rusty spot were monitored throughout the growing seasons of 1999 to 2001. Graphical and statistical analysis revealed that disease increased from the shuckoff stage of fruit development until 60 days after full bloom; epidemics typically lasted from 17 to 30 days. An analysis of fruit growth indicated that the early-season epidemic coincided with the first stage of stone fruit development, physiologically characterized as the period of cell division. During this period, as fruit growth slowed and approached initiation of pit-hardening, the rate of disease increase slowed. Since fruit infection was greatest during the period of fruit growth, disease progression was modeled as a function of plant growth instead of time. Temporal analysis revealed that the logistic function was appropriate for describing both growth processes, and a synchronous logistic/logistic composite disease progression/fruit growth model was fit to all data sets. No change in disease levels occurred during midseason, which coincided with the second stage of fruit development, a period of slow growth. Subsequently, disease incidence and severity significantly declined on average by $26 \%$ and 1.3 lesions per fruit, respectively, during the 20 to 30 days prior to harvest. This decline phase coincided with the third stage of fruit growth, the period of cell enlargement and coloration. These disease reductions may be related to physical changes in fruit size and pigmentation, as opposed to resistance development, causing younger, less established lesions to become undetectable.
\end{abstract}

Additional keywords: epidemiology, Podosphaera leucotricha, powdery mildew, Prunus persica

Rusty spot of peach (Prunus persica (L.) Batsch) is a serious problem on fruit of susceptible cultivars and can be found throughout the United States (12). This disease is reportedly caused by the apple powdery mildew fungus Podosphaera leucotricha (Ellis \& Everh.) E.S. Salmon $(15,19)$; however, controlled experiments have not been conclusive, and it is possible that additional causal agents exist. Infection results in the formation of small orange-to-brown lesions, 4 to $6 \mathrm{~mm}$ in diameter, that usually increase in size to cover large areas of the fruit surface; multiple lesions often coalesce. As lesions age, the trichomes detach and the epidermal cells become lignified, causing the affected surface to appear smooth and russeted, rendering the fruit unmarketable.

Signs of the pathogen are generally absent, as $P$. leucotricha does not grow well on peach $(2,3,12,21)$. However, sparse mycelial strands and powdery mildew-like spores have been observed on young le-

Corresponding author: N. Lalancette

E-mail: lalancette@aesop.rutgers.edu

Accepted for publication 4 November 2002.

Publication no. D-2003-0203-02R

(C) 2003 The American Phytopathological Society sions (6). Infection of other plant parts, particularly leaves and stems, has not been reported. In contrast, infection by the true peach powdery mildew pathogen, Sphaerotheca pannosa, results in leaves, shoots, and fruit becoming covered by abundant white mycelium, conidiophores, and conidia $(11,23)$

Rusty spot is economically important in New Jersey peach orchards. Incidence of fruit infection can approach $100 \%$ on highly susceptible cultivars when left unprotected. Estimates of crop losses have ranged from \$27 per hectare in 1996 to as much as \$504 per hectare in 1997 (17). Although the spatial characteristics of epidemics have been examined $(7,20)$, quantitative studies of the temporal aspects have not been conducted. Consequently, the optimum timing for fungicide applications has not yet been determined. Current recommendations stipulate protection of fruit throughout the season, from shucksplit until harvest (12). The shuck-split stage occurs when growth of the young fruit causes the surrounding calyx to split, exposing the fruit surface for the first time. An epidemiological study was conducted to describe disease progression over the entire growing season and to determine the temporal period or periods during which peach fruit become infected. Such basic knowledge of disease development should allow for more specific recommendations for fungicide use. A report of partial findings was previously presented (10).

Fruit growth and development in peach and other stone fruits follows a doublesigmoid growth pattern $(9,22)$. Peach fruit are susceptible to infection by many fungal pathogens only during specific stages of this developmental pattern. For example, susceptibility to $S$. pannosa has been observed during the early fruit growth phase (23), while that for Monilinia fructicola, causal agent of brown rot, has been reported during the early and late fruit growth stages (1). Therefore, another objective of this study was to determine if any association exists between rusty spot development and the various fruit growth stages. Knowledge of the phenological periods during which fruit are susceptible is critical for efficient utilization of disease control tactics.

\section{MATERIALS AND METHODS}

Experimental sites. Disease and fruit growth observations were made in two separate peach orchards having a history of moderate to high incidence of rusty spot. The first site, located in Deerfield, NJ, consisted of a block of highly susceptible 'Jerseyqueen' (JQ) trees planted at $5.5 \times$ $7.6 \mathrm{~m}$ row spacing. These trees, previously managed by a commercial grower, were 21 years old and grafted on 'Lovell' rootstock. The second site was an experimental orchard located at the Rutgers Agricultural Research and Extension Center. This block consisted of the cultivar 'Jerseyglo' (JG) grafted on 'Lovell' rootstock and had a history of moderate incidence of rusty spot. Trees were 4 years old and planted on a $7.6 \times 7.6 \mathrm{~m}$ row spacing. This site was located approximately $4 \mathrm{~km}$ from the JQ site.

Disease and fruit growth assessment. The JQ and JG orchards were divided into five and four blocks, respectively, of approximately 40 trees per block. In each year of the study, one tree was randomly selected from each block for observation. During each assessment, a total of 40 fruit were arbitrarily picked from each replicate tree. The total number of rusty spot lesions observed on each fruit was recorded. These data were used to calculate disease incidence as proportion of infected fruit and disease severity as average number of lesions per fruit. 
Fruit growth was monitored by estimating fruit volume and recording fruit weight over time. Fruit measurements consisting of length (L), width parallel to the suture $\left(\mathrm{W}_{1}\right)$, and width perpendicular to the suture $\left(\mathrm{W}_{2}\right)$ were used to estimate fruit volume using the formula: volume = $4 / 3 \pi(\mathrm{L} / 2)\left(\mathrm{W}_{1} / 2\right)\left(\mathrm{W}_{2} / 2\right)$, where $\mathrm{L} / 2, \mathrm{~W}_{1} / 2$, and $\mathrm{W}_{2} / 2$ represent the semiaxes of an ellipsoid. At each assessment of JQ, volume was estimated on 20 fruit arbitrarily selected from the 40 harvested fruit; fruit weight was also recorded for these same 20 fruit. On JG, only fruit weight was recorded using all 40 harvested fruit.

Assessments of the JQ cultivar began in May at $100 \%$ shuck-off and continued through harvest at the end of August. A fruit has attained the shuck-off stage when its calyx, the tissue that surrounds the fruit, has completely fallen away. Totals of 15 , 14 , and 15 assessments were performed in 1999, 2000, and 2001, respectively. In 1999, fruit were examined on a weekly basis; however, to allow for better resolution of disease progress and fruit growth during the early portion of the epidemics in 2000 and 2001, assessments were performed twice weekly early in the season and once every 2 weeks from mid- to lateseason. Assessments on the smaller JG trees were performed only during spring of 2000 and 2001, beginning at 100\% shuckoff in early May and ending in early to mid-June. Observations were made twice per week for a total of eight and nine assessments in 2000 and 2001, respectively. Fruit volume measurements were taken in all 3 years of the study at the JQ site, while fruit weight was recorded at both sites in 2000 and 2001. All assessments during each year were performed on the same replicate trees chosen at the beginning of each growing season.

Temporal analysis. Disease progress curves for incidence and severity data were plotted for each combination of cultivar and year. Similarly, fruit growth curves were generated for the volume and weight variables. These full-season graphs were examined visually for presence of any distinct phases and coincidental patterns of growth. Regression analyses were then used to model and compare growth processes within each identified phase or segment.

To mathematically describe the nature of the disease increase phase of each epidemic, three different analytical disease progress models, the monomolecular, logistic, and Gompertz, were fit to the disease incidence data (5). Similarly, the logistic and Gompertz models were fit to the fruit volume and weight data obtained during this same period. Each disease progress model, as well as each fruit growth model, was fit using nonlinear regression (NLIN procedure, Statistical Analysis System v8.0, SAS Institute, Cary, NC) to allow estimation of the carrying capacity, $K$, and to avoid underestimation of rates of disease increase, $r$ (16). All regression analyses were performed using the GaussNewton iterative method with partial derivatives explicitly specified. Appropriateness of model fit was determined by examining relative variation of the $r$ and $K$ parameter estimates and by examining plots of standardized residuals.

Epidemic phases that lacked curvature were temporally analyzed by fitting straight lines to the disease incidence and severity data. Interest was in testing significance of the slope parameter estimates to determine if disease levels were remaining constant or changing; in a linear regression context, this test is equivalent to the $F$ test for model significance. Model fit was evaluated by examining adjusted coefficients of determination and plots of standardized residuals.

Disease/fruit growth association and modeling. Mean values of disease incidence, disease severity, fruit volume, and fruit weight were calculated for each replicate tree at each assessment date. Separate correlation analyses, comparing each disease variable to each fruit size variable, were executed for each phase of the epidemics on both cultivars. In all cases, Pearson product-moment correlation coefficients were calculated using the CORR procedure of SAS v8.0.

The quantitative relationship between disease progression and fruit growth was mathematically described using composite models that incorporate parameters for both pathogen and plant growth (14). This approach required determination of the model form and the temporal relationship between the disease and plant growth processes. The appropriate composite model form, either similar or dissimilar, was based on results of the separate temporal analysis for each growth process. The appropriate temporal relationship between the two growth processes can be either synchronous or asynchronous. Since rusty spot lesions first appear at the shuck-off stage, it was assumed that infection took place when the fruit are first exposed to the environment. Thus, for the purposes of developing composite models, the appropriate temporal relationship was considered to be synchronous. Selected composite models were fit to data from each site and year using nonlinear regression with partial derivatives estimated via the secant method (NLIN procedure, DUD method, SAS v8.0).

Sampling validation. Two experiments were conducted to validate the use of a consecutive destructive sampling technique on the same experimental units (trees). In the first experiment, disease incidence and severity on trees that were sampled over time (for determining disease progress) were compared with disease levels on trees that had never been sampled. In 2000, on day 168 , a one-time assessment was per- formed on 32 trees selected arbitrarily from the entire JQ block. Means from these trees were compared with those obtained from consecutively sampled trees on days 160 (8 samples) and 173 (9 samples). In 2001, disease assessments were performed on five previously nonsampled trees, one randomly chosen from each of the JQ blocks, on days 169 and 204. Means from these trees were compared with those obtained from consecutively sampled trees assessed on the same days, which correspond to 10 and 13 samples, respectively. All means were compared using Fisher's LSD test in the GLM procedure of SAS v8.0.

The sample population of fruit on each tree was limited. Thus, another concern was that removal of a large amount of fruit, as a result of the multiple destructive samplings, might in itself directly affect disease incidence and severity. To test for this effect in 2001, three peach trees were selected in a 'Loring' block having a history of moderate levels of rusty spot. Using the same sampling approach as described for assessing disease on the JQ and JG trees, a total of 15 consecutive samples was collected from each of the three trees on the same day. Fruit in odd-numbered samples were assessed for rusty spot; evennumbered samples were discarded. The relationship between sample number and disease level was examined graphically and by the linear regression using the REG procedure of SAS v8.0.

\section{RESULTS}

The full-season disease progress curves from the JQ block indicated the presence of three segments or phases: (i) early curvilinear increase in disease during spring from days 135 to 170 , (ii) no change in disease during summer between days 170 and 210, and (iii) final decrease in disease prior to harvest from days 210 to 230 . The early-season 2000 and 2001 data from the JG block also showed the first segment.

Early-season phase. Rusty spot incidence and severity increased in each year of the study during the early period of fruit development from shuck-off to pithardening (Fig. 1). In the JQ orchard, disease incidence and severity increased rapidly to maximum levels during the period from days 135 to 175 . Similar rapid increases of disease were observed in the JG block. However, disease incidence and severity on this cultivar were $\leq 50 \%$ of that observed on the JQ. Furthermore, the period of increase was somewhat shorter on JG, occurring from days 132 to 150 .

Epidemic development was also examined in relation to peach phenology. Of particular importance was disease occurrence relative to the time of full bloom, which was defined as $75 \%$ flowers open. In the $1999 \mathrm{JQ}, 2000 \mathrm{JQ}$, and $2000 \mathrm{JG}$ experiments, epidemic onset occurred at 32 to 34 days after full bloom (AFB), and 
disease incidence reached a maximum at approximately 60 days AFB (Figs. 2 and $3)$. In 2001, the time of full bloom was delayed on both cultivars relative to previous years by 9 to 12 days. In this year, 27 days AFB for JQ and JG, respectively. Disease incidence in the JQ orchard still reached a maximum at about 60 days AFB. However, the epidemic in the JG orchard was substantially shorter, attaining a maximum disease level at only 40 days AFB. Nevertheless, in both orchards, termination of the disease inepidemic onset occurred sooner at 23 and

crease phase coincided with initiation of pit-hardening.

Disease progress during the early-season phase was synchronized with the first sigmoidal growth phase of the fruit. On JQ fruit, the greatest increase in disease incidence was observed during days 140 to 150, a period of rapid fruit growth (Fig. 2). Similarly, the rate of fruit infection decreased at approximately the same time as fruit growth was slowing, from days 155 to 170. A similar but less obvious synchronization between disease progress and fruit growth occurred in JG fruit (Fig. 3). For
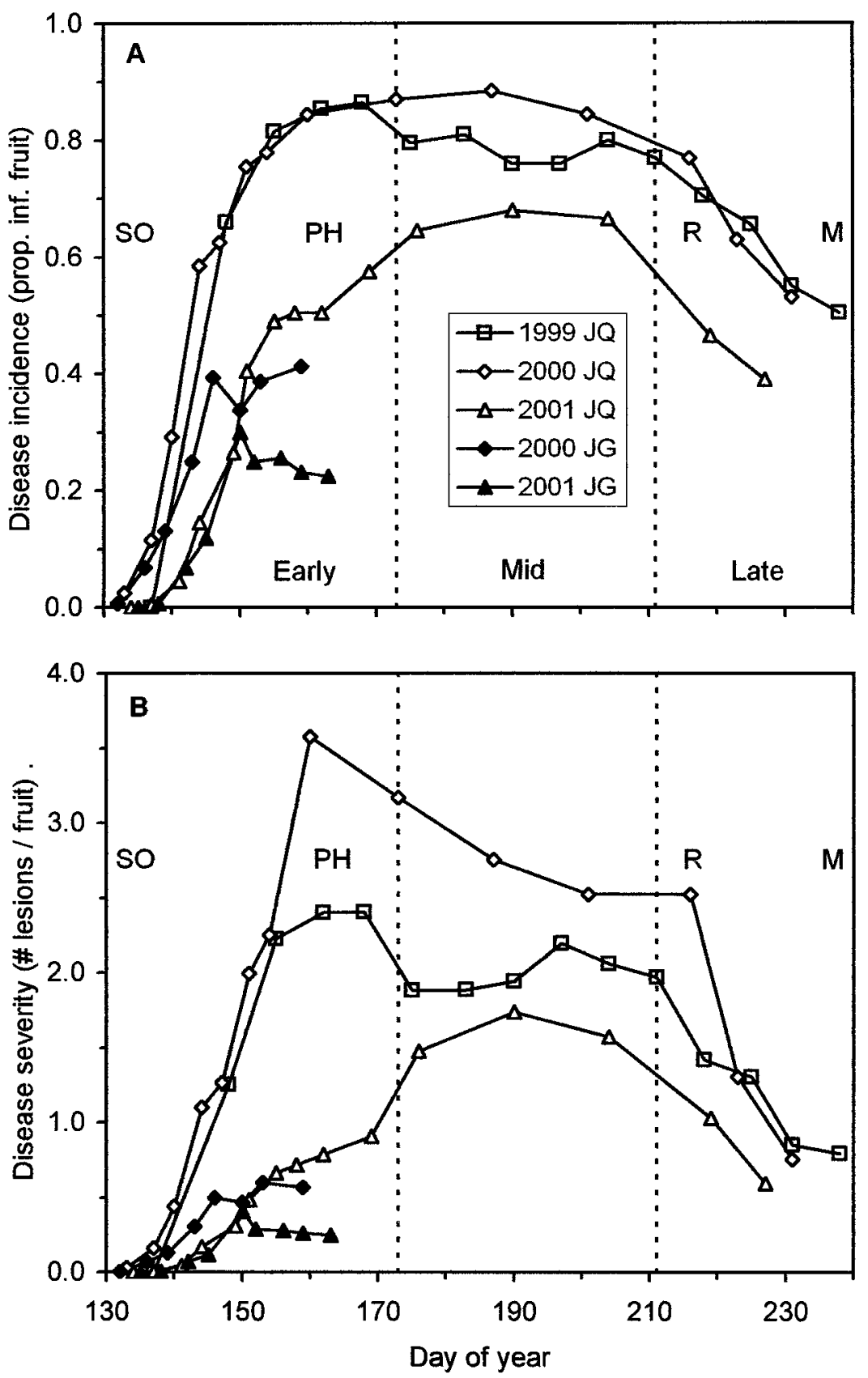

Fig. 1. Progression of peach rusty spot epidemics on 'Jerseyqueen' (JQ) and 'Jerseyglo' (JG) peach during 1999, 2000, and 2001. Early-season phenological phases consist of shuck-off (SO) and pithardening $(\mathrm{PH})$; late-season phases are initiation of ripening $(\mathrm{R})$ and maturation $(\mathrm{M})$ at harvest. Disease incidence, A, and severity, B, data points are averages of five (JQ) and four (JG) replicate trees with 40 fruit examined per tree. this cultivar, the epidemic rate decreased prior to slowing of fruit growth, particularly during the shorter epidemic in 2001. Linear correlation analysis of data from the early phase indicated that disease incidence and severity were strongly associated with fruit volume and weight (Table 1). In both orchards, all 14 correlation coefficients were highly significant $(P<0.0001)$.

Mid-season phase. Very little change in disease incidence was observed during the period from late spring through summer (Fig. 1A). The change in disease severity for 1999 and 2001 showed no apparent increase or decrease during this same time frame (Fig. 1B). However, the 2000 disease severity data showed a slight decrease in lesion numbers during this midseason period.

Results of the linear regression analyses revealed no relationship between disease and time during the midseason phase of the epidemics (Table 2). All coefficients of determination were very low, and five of the six slope estimates were not significantly different from zero $(P>0.05)$. The 2000 disease incidence slope was significantly different from zero; however, the rate of change, $-0.24 \%$ per day, was very low. In all regression analyses conducted for this stage, examination of standardized residuals did not indicate that another model would have provided a better fit.

During the 1999 and 2001 midseason epidemic phases, fruit volume increased slowly, marking the beginning of the second sigmoidal growth pattern (Fig. 2). However, during this same period in 2000 , fruit volume increased at a much greater rate than in the other 2 years. Nevertheless, disease incidence and severity were not correlated with either fruit volume or weight during this phase of the epidemic (Table 1).

Late-season phase. Disease incidence and severity decreased during the 3- to 4week period prior to harvest (Fig. 1). This phase coincided with the period from approximately 1 week prior to initiation of ripening to full fruit maturation. On average, disease incidence was reduced by $26 \%$ and disease severity by 1.3 lesions per fruit across all 3 years of the study.

Linear regressions of the incidence and severity data from these late season decline phases were highly significant (Table 2). In all six cases, the slope parameter estimates were negative. Although the adjusted coefficients of determination were low to moderate, ranging from 0.17 to 0.60 , examination of standardized residuals did not indicate that a nonlinear model would have been more appropriate.

Fruit volume and weight increased significantly during the final epidemic phase (Fig. 2G to I). This typical period of final "fruit swell" was most evident in 1999 and 2001. During this stage, disease incidence and severity were negatively correlated with both fruit volume and weight; all 10 

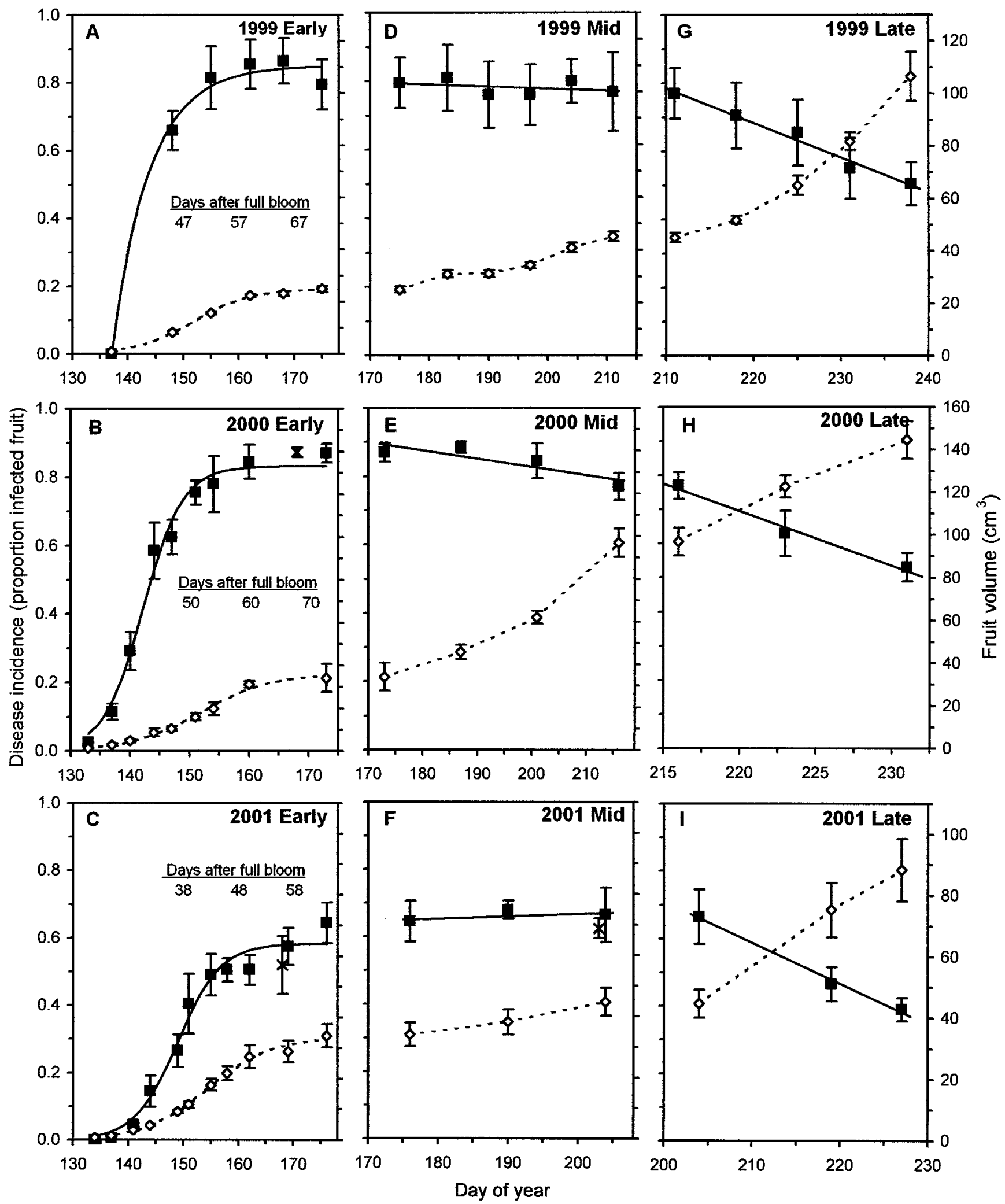

Fig. 2. Temporal modeling of peach rusty spot disease progress (solid lines and solid squares) and fruit growth (dashed lines and open diamonds) in a 'Jerseyqueen' orchard during the 1999, 2000, and 2001 growing seasons. Fitted curves in the early-season growth phase (A to C) represent the predicted values for the logistic model except for disease progress in 1999, in which the monomolecular function provided the best fit. Fitted lines for disease incidence in the midseason (D to F) and late-season (G to I) phases represent predicted values based on a linear model; no models were fit to the fruit growth data during these periods. Observed data points are means of five replicate trees; bars represent standard error of the mean. Single data points (marked $\times$ ) in figures $\mathbf{B}, \mathbf{C}$, and $\mathbf{F}$ represent assessments performed on trees sampled only once during the growing season; points in $\mathbf{C}$ and $\mathbf{F}$ were offset by one day to allow easier viewing. Note graphs of adjacent phases overlap by one data point; beginning and ending data points of the midseason phase are final and starting data points for the early- and late-season phases, respectively. 
correlation coefficients were significant and ranged from -0.52 to -0.75 (Table 1 ).

Disease progression/fruit growth modeling. The logistic model, followed closely by the Gompertz model, was found to provide the best fit to the early season disease progress data in four of the five combinations of orchard and year (Table $3)$. Mean total percent relative variation $\left(\mathrm{RV}_{\mathrm{T}}\right)$ for the $r$ and $K$ parameters across these four combinations was $33.2 \%$ for the logistic model, $34.5 \%$ for the Gompertz model, and $55.0 \%$ for the monomolecular model. The one exception occurred in 1999, when the monomolecular model provided the best fit (Table 3); $\mathrm{RV}_{\mathrm{T}}$ values in that year for the logistic and Gompertz models were 166 and $183 \%$, respectively.
In 1999, an insufficient number of observations early in the season made it difficult to detect any nonlinear relationship during this phase of the epidemic (Fig. 2A). Initial disease levels $\left(y_{0}\right)$ were appropriately estimated to be very low when the best model was fit to the data; in 1999 and 2001, the confidence interval for $y_{0}$ included zero.

Of the two sigmoid models examined for fruit growth, the logistic model provided the best quantitative description of either fruit volume or weight over time (Table 3). In all seven combinations of year, orchard, and dependent variable (volume and weight), mean $\mathrm{RV}_{\mathrm{T}}$ was 19.1 and $28.8 \%$ for the logistic and Gompertz models, respectively. Of the two dependent variables examined on JQ, the logistic model fit fruit
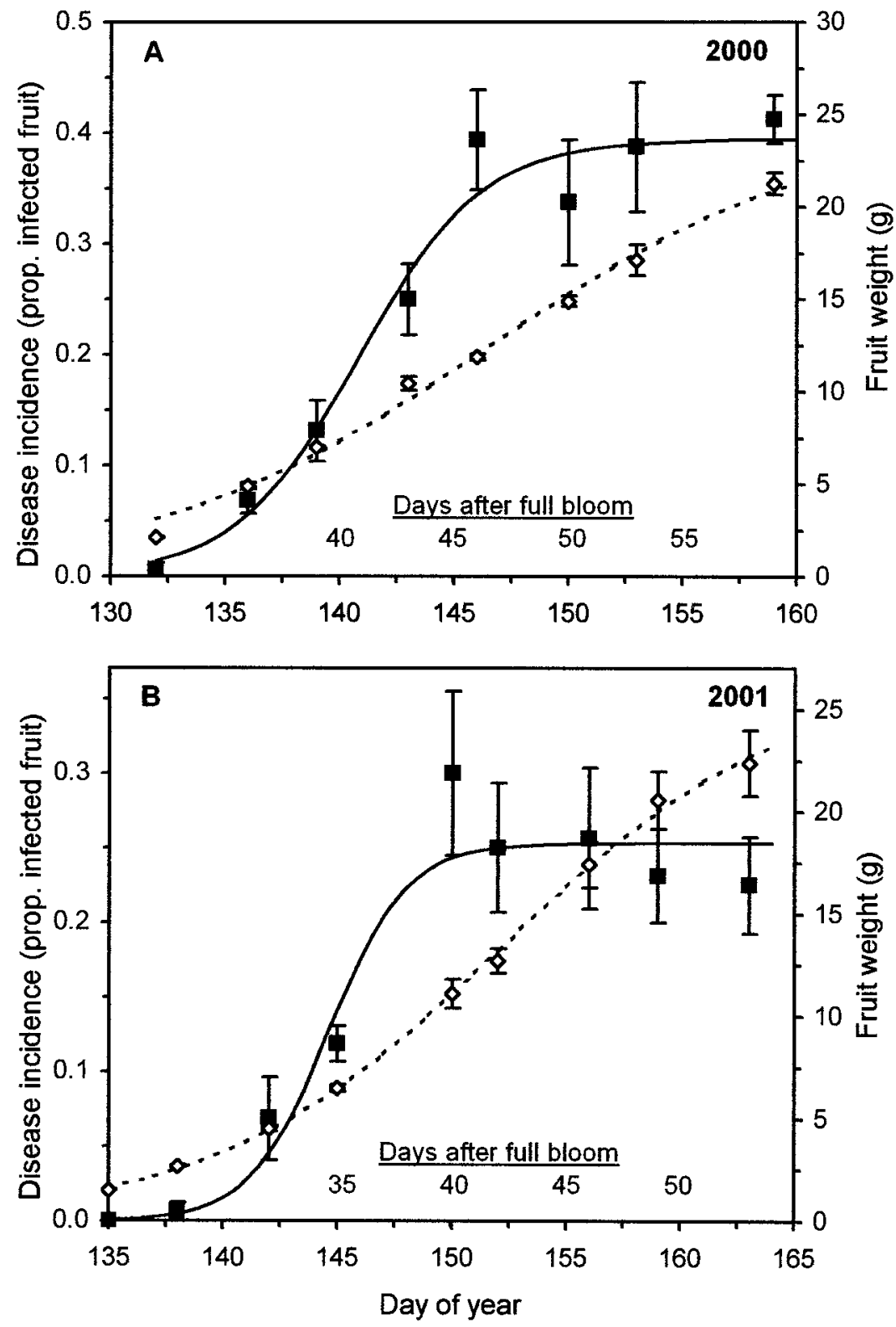

Fig. 3. Temporal modeling of peach rusty spot disease progress (solid lines and solid squares) and fruit growth (dashed lines and open diamonds) during the early-season phase of peach fruit growth in a 'Jerseyglo' orchard during 2000 and 2001. Curves represent the predicted values from fitting a logistic model to the observed data. Data points are means of four replicate trees; bars represent standard error of the mean.

weight data $\left(\mathrm{RV}_{\mathrm{T}}=17.5 \%\right)$ better than volume data $\left(\mathrm{RV}_{\mathrm{T}}=26.7 \%\right)$ in 2000 , but no difference was observed in $2001\left(\mathrm{RV}_{\mathrm{T}}\right.$ was 21.5 and $21.6 \%$, respectively).

Given that the appropriate model forms for disease progression and fruit growth in 2000 and 2001 are logistic and that the two processes occur simultaneously, the proper composite growth function is a synchronous logistic/logistic model (14):

$$
y=K_{1} /\left\{1+B\left[\left(K_{2}-x\right) / x\right]^{r_{g}}\right\}
$$

Although this composite model could be fit to the 1999 data, the temporal analysis indicated that the monomolecular function was most appropriate for the disease component of that data set. Consequently, a synchronous monomolecular/logistic composite model was derived (14); the final integrated form is:

$$
y=K_{1} /\left\{1-B \exp \left[r_{g} \log \left(K_{2} / x\right)-1\right]\right\}
$$

In both of these derived models, $y=$ proportion of infected fruit; $x=$ fruit size (volume or weight); $r_{g}$ is the ratio of the rate of increase of disease, $r_{1}$, to the rate of plant growth, $r_{2} ; K_{1}$ and $K_{2}$ are maximum values for disease and fruit size, respectively; and $B$ is an additional parameter that incorporates the constants of integration and influences shape of the model curves. In fitting these models to the data using nonlinear regression analysis, the $K_{2}$ parameter was set as a constant equal to the maximum volume or weight observed +0.5 . This modification was necessary to avoid undefined intermediate values for the partial derivatives calculated during the iterative process for minimizing the residual sums of squares.

The composite models provided good to excellent fits of disease progression as a function of fruit growth (Table 4). Relative variation of the parameter estimates was particularly low $\left(\mathrm{RV}_{\mathrm{T}}<30 \%\right)$ for the 2000 and $2001 \mathrm{JQ}$ data, regardless of whether fruit volume or weight was used as the independent variable. However, somewhat higher values of $\mathrm{RV}_{\mathrm{T}}$ were obtained for the JG data (Table 4), although this variation was also observed in the temporal analysis (Table 3). This difference in variability between cultivars was also evident in graphs of the observed versus predicted values (Fig. 4). The observed data points were somewhat closer to the predicted curves for JQ (Fig. 4A and B), particularly for larger fruit sizes, than for JG (Fig. 4C and D). The composite logistic/logistic model also produced curvilinear shapes that were different from a sigmoid pattern (Fig. 4A).

Sampling validation. Disease levels on trees destructively sampled multiple times per season were not significantly different from levels on trees sampled only once per season (Table 5). This lack of significant difference between the two sample treatments (single versus multiple assessment) was valid for both disease incidence and 
severity estimates after as many as 13 samplings, for a total of 520 fruit removed per tree. In addition, the sampling procedure itself was found to have no effect on disease levels; disease incidence and severity remained constant as sample number increased. The slopes of the lines fit to the incidence and severity data were not significantly different from zero $(P=0.58$ and 0.92 , respectively).

\section{DISCUSSION}

One of the most critical components of a plant pathosystem is the timing of infec- tion. Such information is vital for the timely and efficacious deployment of fungicides or biological control agents, and disease management programs are inherently inefficient without this knowledge. According to current recommendations for rusty spot management in New Jersey,

Table 1. Correlation between disease and fruit growth during three phases of peach rusty spot epidemics on two different cultivars during 1999 to 2001

\begin{tabular}{|c|c|c|c|c|c|c|c|c|c|c|}
\hline \multirow[b]{3}{*}{ Orchard } & \multirow{3}{*}{$\begin{array}{l}\text { Epidemic } \\
\text { phase }\end{array}$} & \multirow[b]{3}{*}{ Year } & \multicolumn{4}{|c|}{ Disease incidence $^{a}$} & \multicolumn{4}{|c|}{ Disease severity $^{\mathbf{a}}$} \\
\hline & & & \multicolumn{2}{|c|}{ Fruit weight } & \multicolumn{2}{|c|}{ Fruit volumeb } & \multicolumn{2}{|c|}{ Fruit weight } & \multicolumn{2}{|c|}{ Fruit volume $^{b}$} \\
\hline & & & $r^{\mathrm{c}}$ & $P$ value & $r^{\mathrm{c}}$ & $P$ value & $r^{\mathrm{c}}$ & $P$ value & $r^{c}$ & $P$ value \\
\hline \multirow[t]{9}{*}{ Jerseyqueen } & Early & 1999 & $\ldots$ & & 0.79 & $<0.0001$ & $\ldots$ & & 0.66 & $<0.0001$ \\
\hline & & 2000 & 0.79 & $<0.0001$ & 0.78 & $<0.0001$ & 0.77 & $<0.0001$ & 0.80 & $<0.0001$ \\
\hline & & 2001 & 0.80 & $<0.0001$ & 0.80 & $<0.0001$ & 0.80 & $<0.0001$ & 0.80 & $<0.0001$ \\
\hline & Mid & 1999 & $\ldots$ & $\ldots$ & 0.11 & 0.5506 & $\ldots$ & $\ldots$ & 0.18 & 0.3334 \\
\hline & & 2000 & -0.44 & 0.0545 & -0.36 & 0.1199 & -0.06 & 0.7861 & 0.02 & 0.9395 \\
\hline & & 2001 & -0.19 & 0.4939 & -0.17 & 0.5488 & -0.10 & 0.7459 & -0.06 & 0.8259 \\
\hline & Late & 1999 & $\ldots$ & $\ldots$ & -0.57 & 0.0031 & $\ldots$ & $\ldots$ & -0.54 & 0.0058 \\
\hline & & 2000 & -0.59 & 0.0251 & -0.53 & 0.0522 & -0.75 & 0.0021 & -0.70 & 0.0052 \\
\hline & & 2001 & -0.57 & 0.0273 & -0.56 & 0.0308 & -0.53 & 0.0406 & -0.52 & 0.0461 \\
\hline \multirow[t]{2}{*}{ Jerseyglo } & Early & 2000 & 0.83 & $<0.0001$ & $\ldots$ & $\ldots$ & 0.86 & $<0.0001$ & $\ldots$ & $\ldots$ \\
\hline & & 2001 & 0.76 & $<0.0001$ & $\ldots$ & $\ldots$ & 0.68 & $<0.0001$ & $\ldots$ & $\ldots$ \\
\hline
\end{tabular}

a Disease incidence assessed as proportion of infected fruit; severity assessed as no. lesions per fruit.

b Volume estimated by substituting semiaxis measurements into the formula for an ellipsoid.

c Pearson product-moment correlation coefficient.

Table 2. Temporal analysis of mid- and late-season phases of peach rusty spot epidemics in a 'Jerseyqueen' orchard during 1999 to 2001

\begin{tabular}{|c|c|c|c|c|c|c|c|c|}
\hline \multirow[b]{2}{*}{ Epidemic phase } & \multirow[b]{2}{*}{ Year } & \multirow[b]{2}{*}{ Disease } & \multicolumn{2}{|c|}{ Error } & \multicolumn{4}{|c|}{ Model $^{a}\left(\mathbf{H}_{\mathrm{o}}:\right.$ slope $=0 ; \mathbf{H}_{\mathrm{a}}:$ slope $\left.\neq 0\right)$} \\
\hline & & & df & Mean square & Slope & Intercept & $r^{2 a}$ & $P>F$ \\
\hline \multirow[t]{6}{*}{ Mid } & 1999 & Incidence & 28 & 0.0356 & -0.0006 & 0.9026 & -0.0339 & 0.8276 \\
\hline & & Severity & 28 & 0.6875 & 0.0049 & 1.0376 & -0.0299 & 0.6946 \\
\hline & 2000 & Incidence & 18 & 0.0063 & -0.0024 & 1.3083 & 0.1621 & 0.0443 \\
\hline & & Severity & 18 & 1.4466 & -0.0150 & 5.6637 & -0.0107 & 0.3833 \\
\hline & $2001^{\mathrm{b}}$ & Incidence & 12 & 0.0183 & 0.0007 & 0.5250 & -0.0784 & 0.8192 \\
\hline & & Severity & 12 & 0.3875 & 0.0034 & 0.9393 & -0.0781 & 0.8134 \\
\hline \multirow[t]{6}{*}{ Late } & 1999 & Incidence & 23 & 0.0406 & -0.0102 & 2.9250 & 0.1650 & 0.0251 \\
\hline & & Severity & 23 & 0.4329 & -0.0435 & 11.0425 & 0.2689 & 0.0046 \\
\hline & $2000^{\mathrm{b}}$ & Incidence & 12 & 0.0118 & -0.0160 & 4.2114 & 0.4305 & 0.0065 \\
\hline & & Severity & 12 & 0.3391 & -0.1188 & 28.0423 & 0.6038 & 0.0007 \\
\hline & 2001 & Incidence & 13 & 0.0159 & -0.0121 & 3.1355 & 0.4544 & 0.0035 \\
\hline & & Severity & 13 & 0.2582 & -0.0416 & 10.0720 & 0.3673 & 0.0098 \\
\hline
\end{tabular}

${ }^{a}$ Results of linear regression analysis of disease incidence (proportion infected fruit) or disease severity (no. lesions per fruit) over time; $F$ test is equivalent to test of slope significance.

b Single outlier removed from data sets prior to analysis.

Table 3. Best models for describing disease progression and fruit growth during the early-season growth phase of peach rusty spot epidemics in two different orchards during 1999 to 2001

\begin{tabular}{|c|c|c|c|c|c|c|c|c|c|c|c|}
\hline \multirow[b]{2}{*}{ Orchard $^{\mathbf{a}}$} & \multirow{2}{*}{$\begin{array}{c}\text { Dependent } \\
\text { variable }^{b}\end{array}$} & \multirow[b]{2}{*}{ Year } & \multirow{2}{*}{$\begin{array}{l}\text { Selected } \\
\text { model }^{c}\end{array}$} & \multirow[b]{2}{*}{$\mathbf{N}$} & \multicolumn{3}{|c|}{ Parameter estimate } & \multicolumn{3}{|c|}{ Parameter std. error } & \multirow[b]{2}{*}{$\mathbf{R} \mathbf{V}_{\mathbf{T}}{ }^{\mathbf{d}}$} \\
\hline & & & & & $r$ & $K$ & $y_{0}$ & $r$ & $K$ & $y_{0}$ & \\
\hline \multirow[t]{6}{*}{$\overline{\mathrm{JQ}}$} & Dis. incidence & 1999 & Mono. & 30 & 0.1469 & 0.8512 & -0.0019 & 0.0425 & 0.0448 & 0.0761 & 34 \\
\hline & Dis. incidence & 2000 & Logistic & 45 & 0.3005 & 0.8319 & 0.0495 & 0.0480 & 0.0311 & 0.0205 & 19 \\
\hline & Dis. incidence & 2001 & Logistic & 55 & 0.2575 & 0.5824 & 0.0120 & 0.0511 & 0.0293 & 0.0090 & 25 \\
\hline & Fruit volume & 1999 & Logistic & 30 & 0.1932 & 24.93 & 1.3474 & 0.0209 & 0.6746 & 0.3889 & 14 \\
\hline & Fruit weight & 2000 & Logistic & 45 & 0.1454 & 42.52 & 1.7555 & 0.0167 & 2.5377 & 0.4808 & 18 \\
\hline & Fruit weight & 2001 & Logistic & 55 & 0.1616 & 33.39 & 1.0677 & 0.0244 & 2.1497 & 0.4631 & 22 \\
\hline \multirow[t]{4}{*}{ JG } & Dis. incidence & 2000 & Logistic & 32 & 0.3740 & 0.3944 & 0.0141 & 0.0970 & 0.0239 & 0.0114 & 32 \\
\hline & Dis. incidence & 2001 & Logistic & 36 & 0.5929 & 0.2530 & $8.5 \times 10^{-4}$ & 0.3020 & 0.0162 & 0.0024 & 57 \\
\hline & Fruit weight & 2000 & Logistic & 32 & 0.1350 & 24.74 & 3.0936 & 0.0106 & 1.3881 & 0.2686 & 14 \\
\hline & Fruit weight & 2001 & Logistic & 36 & 0.1600 & 26.71 & 1.6160 & 0.0178 & 2.1523 & 0.3323 & 19 \\
\hline
\end{tabular}

a Peach orchards were composed of 'Jerseyqueen' (JQ) or 'Jerseyglo' (JG) trees.

b Nonlinear regression analyses performed on disease incidence (proportion infected fruit), fruit volume ( $\left.\mathrm{cm}^{3}\right)$, or fruit weight ( $\mathrm{g}$ ) data. The independent variable, day of year (doy), was scaled so that the first assessment occurred on day 0: in 1999, day = doy -137 ; in 2000 , day = doy -133 ; and in 2001, day $=$ doy -134

c Models for describing disease progress (monomolecular, logistic, and Gompertz) and fruit growth (logistic and Gompertz) were fit to the data via nonlinear regression analyses using the Gauss-Newton iterative method with partial derivatives explicitly specified.

d Total relative variation for $r$ and $K$ parameters calculated as $\mathrm{RV}_{\mathrm{T}}=\mathrm{RV}_{r}+\mathrm{RV}_{\mathrm{K}}$, where relative variation (RV) of parameter estimates was calculated as (S.E.estimate/estimate) $* 100$. 
peach growers begin fungicide applications at shuck-split and continue on an 8- to 10day schedule throughout the season (12). However, based on results of the temporal analysis conducted in this study, we conclude that control measures need only be applied during the early-season phase of the epidemic; no increase in disease was observed to occur during the mid- or lateseason periods. In terms of tree phenology, we predict that disease control is needed from shuck-split, when fruit tissue is first exposed, until 50 days after full bloom, which coincides with the start of pithardening. Once initiated, epidemics typically lasted from 17 to 30 days in duration. Based on these results, it is likely that two to four fungicide applications would be required for control on susceptible cultivars, depending on efficacy and residual activity.

Since this is the first quantitative description of the temporal behavior of peach rusty spot epidemics, results from other studies are not available for comparison. Nevertheless, a comparison with the temporal aspects of peach powdery mildew, as caused by $S$. pannosa, provides some interesting similarities in epidemic behavior. In an earlier study, peach fruit became completely resistant to $S$. pannosa infection at 2 months after bloom (23). This finding compares favorably with our results, which showed that in four out of five cases, no further increase in rusty spot incidence or severity occurred after 60 days following full bloom. Furthermore, the transition of the fruit from susceptible to resistant to infection by $S$. pannosa occurred during the middle of the first fruit growth curve stage, which corresponds to the period just prior to pit-hardening (23). For peach rusty spot, a slowing of the epidemic rate was observed during this same period, culminating in a zero rate at initiation of pithardening.

In terms of stone fruit physiology, stage I is a period of rapid cell division that corresponds to the first sigmoidal increase in fruit size or mass $(9,22)$. Our disease data, as well as those of the earlier study (23), indicate that susceptibility to these two pathogens is greatest during this period. Conversely, initiation of fruit growth stage II, which corresponds to the period of pithardening and slow fruit growth $(9,22)$, appears to be related to the development of ontogenetic resistance to infection by powdery mildew fungi. We observed no increase in rusty spot disease incidence or severity during this midseason phase of the epidemic and fruit development.

Another major objective of this study was to model rusty spot disease progression as a function of fruit growth during the early-season phase. This modeling approach, which is applicable to a type I susceptibility classification $(14,18)$, essentially replaces time with fruit size as the independent variable. This substitution does not necessarily imply a cause and effect relationship; plant growth is merely used as a measure of "biological time." However, evidence indicates that disease development is directly dependent on the production of young, rapidly dividing fruit cells. Thus, modeling rusty spot disease progression as a function of fruit growth can provide important benefits over classic temporal models. For example, variation in temperature, rainfall, or nutrition during the early growing season could alter the rate or extent of fruit growth, thereby indirectly affecting the period of susceptibility. Recent research on peach growth has related relative growth rates of the fruit to degree-days after flowering (8). A composite model would accommodate this change, while a temporal model would not. Composite models would be useful in comparative epidemiological studies to examine the effects of various disease management treatments and compare rates of disease progress relative to fruit growth.

The destructive sampling approach may have influenced the results of the correlation analyses between disease and fruit size during each epidemic phase and the composite modeling during the early phase. Commercial growers perform fruit thin- ning during late spring, at about the time of pit-hardening, to obtain larger fruit at harvest. Given a mature tree bearing 1,500 to 2,000 fruit, a grower would typically remove 900 to 1,400 fruit, resulting in a 60 to $70 \%$ reduction, respectively. In contrast, the trees in our experiment were not thinned in this fashion since fruit were to be removed for assessment throughout the season. Since we removed only 560 to 600 fruit per tree, which corresponds to a 28 to $30 \%$ reduction, smaller fruit would be expected. However, average fruit width at harvest ranged from 5.4 to $6.4 \mathrm{~cm}$, which on a commercial scale corresponds to medium-sized fruit. We suspect this outcome may have resulted from a large percentage of our fruit being removed during the early epidemic phase. Fruit thinning performed before the end of the fruit cell division period (pit-hardening) can stimulate greater numbers of cells and hence potentially larger fruit (24). Regardless of the mechanism by which our fruit attained average size, the pattern and timing of the fruit growth stages were normal compared to prior results $(9,22)$. Thus, we believe that the disease-fruit size correlations and composite models are mostly likely valid. Nevertheless, an examination of these relationships employing nondestructive sampling and commercial thinning practices would provide confirmation of the results.

The logistic model, which provided the best fit to rusty spot epidemics, is typically used to describe pathosystems having secondary infection cycles resulting in contagious disease spread (25). However, little or no sporulation occurs on rusty spot lesions $(6,12,21)$, and evidence of secondary spread has not been observed (20). We propose two possible scenarios, one hostcentric and the other pathogen-centric, which may help to explain this apparent contradiction. In the first scenario, the rate of infection is solely dependent on the availability of susceptible fruit tissue. The synchronization and similarity of form of fruit growth and disease progression, both

Table 4. Peach rusty spot disease progression as a function of fruit growth ${ }^{\mathrm{a}}$ during the epidemic growth phase in two different orchards from 1999 to 2001

\begin{tabular}{|c|c|c|c|c|c|c|c|c|c|c|c|}
\hline \multirow[b]{2}{*}{ Orcharde } & \multirow[b]{2}{*}{ Year } & \multirow{2}{*}{$\begin{array}{l}\text { Fruit size } \\
\text { variable }\end{array}$} & \multicolumn{2}{|c|}{ Error } & \multicolumn{3}{|c|}{ Parameter estimate $^{b}$} & \multicolumn{3}{|c|}{ Parameter std. error ${ }^{b}$} & \multirow[b]{2}{*}{$\mathbf{R} \mathbf{V}_{T}^{\mathrm{d}}$} \\
\hline & & & df & MS & $r_{g}$ & $K_{1}$ & $B$ & $r_{g}$ & $K_{1}$ & $B$ & \\
\hline \multirow[t]{5}{*}{$\overline{\mathrm{JQ}}$} & 1999 & Volume & 27 & 0.0224 & 0.5502 & 0.9028 & 0.1562 & 0.1844 & 0.0821 & 0.0958 & 42.6 \\
\hline & 2000 & Volume & 42 & 0.0162 & 1.8092 & 0.8468 & 0.0270 & 0.3156 & 0.0392 & 0.0193 & 22.0 \\
\hline & 2000 & Weight & 42 & 0.0157 & 1.7981 & 0.8477 & 0.0283 & 0.3052 & 0.0380 & 0.0196 & 21.5 \\
\hline & 2001 & Volume & 52 & 0.0133 & 1.7965 & 0.5756 & 0.0637 & 0.4159 & 0.0364 & 0.0489 & 29.5 \\
\hline & 2001 & Weight & 52 & 0.0127 & 1.9178 & 0.5757 & 0.0512 & 0.4331 & 0.0347 & 0.0404 & 28.6 \\
\hline \multirow[t]{2}{*}{ JG } & 2000 & Weight & 29 & 0.0058 & 2.7615 & 0.3918 & 0.1857 & 0.7703 & 0.0258 & 0.1212 & 34.5 \\
\hline & 2001 & Weight & 33 & 0.0040 & 3.1974 & 0.2580 & 0.0250 & 1.3716 & 0.0169 & 0.0446 & 49.5 \\
\hline
\end{tabular}

a A synchronous logistic/logistic composite disease progression/fruit growth model was fit to all data sets except for 1999, in which a synchronous monomolecular/logistic model was used. All fits were performed using nonlinear regression analyses with the secant method of partial derivative estimation. Fruit volume $\left(\mathrm{cm}^{3}\right)$ or weight $(\mathrm{g})$ was the independent variable and disease incidence (prop. inf. fruit) was the dependent variable.

${ }^{\mathrm{b}}$ For both model types, $r_{g}=r_{1} / r_{2}$, where $r_{1}$ and $r_{2}$ represent the rates of change for disease and fruit growth, respectively; $K_{1}$ is maximum value for disease. The $B$ parameter has different roles in each model.

' Peach orchards were composed of 'Jerseyqueen' (JQ) or 'Jerseyglo' (JG) trees.

d Total relative variation for $r_{g}$ and $K_{1}$ parameters calculated as $\mathrm{RV}_{\mathrm{T}}=\mathrm{RV}_{r}+\mathrm{RV}_{\mathrm{K}}$, where relative variation (RV) of parameter estimates was calculated as (S.E.estimate/estimate) $* 100$. 
following a logistic pattern, support this scenario. More or less available inoculum, as might be exemplified by the JQ and JG orchards, respectively, would determine the extent of infection, but would have no effect on the pattern of disease progress. In the second scenario, the rate of infection is a function of inoculum production on the alternative host, apple. Secondary infection cycles are known to occur for apple powdery mildew (4), and the Richards (sigmoidal form) or Gompertz functions may be appropriate disease progression models (13). In this scenario, disease progression on peach essentially mimics that on apple as the two pathosystems share the same inoculum source.

The occurrence of a disease decline phase just prior to harvest has not been reported for either rusty spot or powdery mildew of peach. For those pathosystems in which disease incidence decreases dur-
Table 5. Effect of repeated fruit sampling on incidence and severity of rusty spot on 'Jerseyqueen' peach during the midseason static epidemic phase in 2000 and 2001

\begin{tabular}{|c|c|c|c|c|c|c|}
\hline Year & $\begin{array}{l}\text { Assessment } \\
\text { day of year }\end{array}$ & $\begin{array}{c}\text { No. of } \\
\text { samples }^{\mathrm{a}}\end{array}$ & $\begin{array}{c}\text { Fruit } \\
\text { removed/tree }\end{array}$ & $\mathbf{N}^{\mathbf{b}}$ & $\begin{array}{l}\text { Mean incidence } \\
\text { prop. inf. fruit }\end{array}$ & $\begin{array}{l}\text { Mean severity } \\
\text { no. lesions/fruit }\end{array}$ \\
\hline \multirow[t]{4}{*}{2000} & 160 & 8 & 320 & 5 & 0.845 & 3.56 \\
\hline & 168 & 1 & 40 & 32 & 0.873 & 3.41 \\
\hline & 173 & 9 & 360 & 5 & 0.870 & 3.17 \\
\hline & & & \multicolumn{2}{|c|}{$\operatorname{LSD}(0.05)$} & 0.089 & 1.63 \\
\hline \multirow[t]{3}{*}{2001} & 169 & 1 & 40 & 5 & 0.520 & 1.06 \\
\hline & 169 & 10 & 400 & 5 & 0.575 & 0.91 \\
\hline & & & \multicolumn{2}{|c|}{$\operatorname{LSD}(0.05)$} & 0.235 & 0.58 \\
\hline \multirow[t]{3}{*}{2001} & 204 & 1 & 40 & 5 & 0.625 & 1.28 \\
\hline & 204 & 13 & 520 & 5 & 0.665 & 1.57 \\
\hline & & & \multicolumn{2}{|c|}{$\operatorname{LSD}(0.05)$} & 0.198 & 0.89 \\
\hline
\end{tabular}

${ }^{a}$ Total number of samples removed from each tree at 40 fruit per sample; table rows with $>1$ sample represent trees consecutively sampled for determination of disease progress.

${ }^{b}$ Number of trees sampled, one per replicate block; on day 168 in 2000, 32 trees were sampled across entire orchard, at 6 to 7 trees per replicate block.

${ }^{c}$ Analysis of variance performed on incidence and severity data with number of samples as the independent classification variable. Three separate analyses were performed, one for each year and assessment period combination; means within a year were compared using Fisher's LSD.
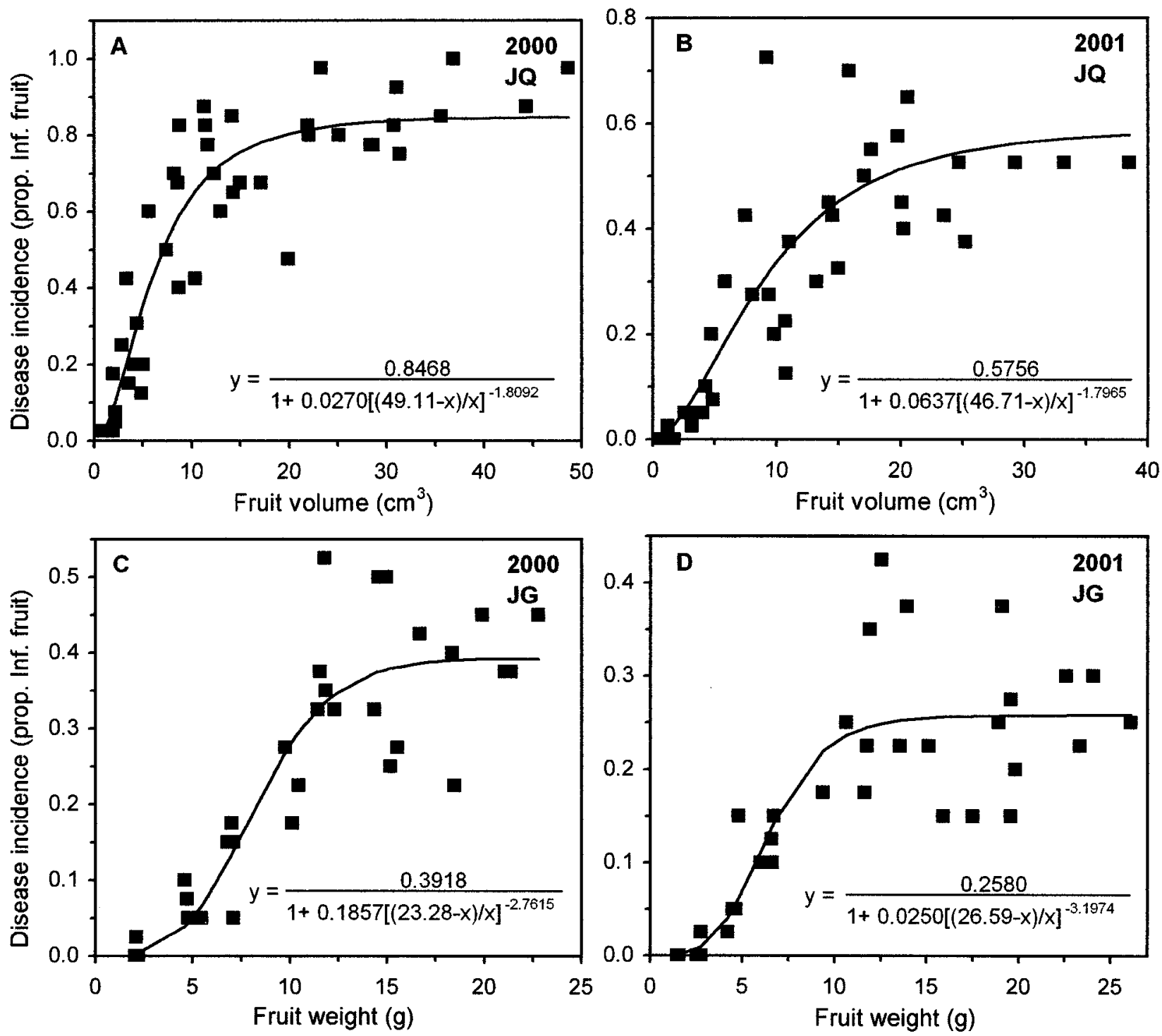

Fig. 4. Disease progression of peach rusty spot as a function of fruit growth in 'Jerseyqueen' (JQ) and 'Jerseyglo' (JG) orchards during the early-season growth phase of epidemics in 2000 and 2001. Data points represent observations of disease incidence and fruit growth, either volume ('Jerseyqueen') or weight ('Jerseyglo'), from single trees. Solid lines represent the predicted values calculated from a synchronous logistic/logistic composite model shown for each data set. 
ing an epidemic, new host tissue may be produced faster than the pathogen can infect it or there may be a loss of diseased tissue (5). These situations cannot explain the results of our study, as the number of fruit per tree was constant from midseason onward. After fertilization during bloom, a period of natural thinning or "fruit drop" occurs, but this event is during late spring, approximately 2 months before the observed disease decline phase. Furthermore, fruit abscission due to rusty spot infection was not observed and has not been previously reported. In our experiment, the only fruit loss was due to brown rot, which occurred during the final assessment at harvest, several weeks after initiation of the rusty spot decline phase.

Although fruit number is constant at the end of the season, a dramatic increase in fruit size occurs just prior to harvest $(9,22)$. Physiologically, this is the period of cell enlargement (growth stage III), which coincided with the observed decline in disease. Unlike the development of ontogenetic resistance believed to occur between the first and second epidemic and fruit growth stages, we believe this late disease decline is purely a physical phenomenon. We propose that certain lesions, perhaps the younger ones incited during the latter part of the epidemic, become undetectable as a result of inadequate colonization and lignification of the epidermal layer. As fruit cells expand, symptoms become imperceptible. In addition, the formation of red coloration during this period may contribute to apparent lesion disappearance. However, older lesions with significant lignification were readily identified regardless of epidermal color.

Most field-based disease assessment techniques rely on visual detection of symptoms or signs. Our results show that visible disease levels do decline at the end of the season. This fact has much practical significance, since fruit that are not visibly injured are sold and do not contribute to crop loss. Thus, our visual assessments relate directly to economic impact. However, further research is needed to determine if disease might still be present at some microscopic level. A detailed histopathological study should be conducted to document microscopic symptomatology and presence of the pathogen over time. Unlike our study, which focused on population phenomena, individual lesions should be tracked with respect to their time of appearance, signs and symptoms, and fate at the end of the season.

Results of the sampling validation experiment indicate that destructive sampling does not affect progression of peach rusty spot epidemics. At several different points during the epidemic, disease levels on trees sampled numerous times were not significantly different from those sampled one time. This result is consistent with microscopic observations of this disease, which reveal that the pathogen does not sporulate well on peach fruit. Since all of the inoculum is believed to come from outside the orchard, removal of infected fruit has no effect on the epidemic. That is, on peach, disease at time $t$ is not dependent on disease at time $t-1$. Results also showed that consecutive destructive sampling did not alter the proportion of infected fruit or the average number of lesions per fruit. We believe this outcome was due to two factors. First, the arbitrary sampling process was unbiased because rusty spot does not noticeably alter fruit dimensions; peaches can very easily be picked without knowing whether they are healthy or infected. Second, since large, mature trees can set approximately 1,500 to 2,000 fruit, many fruit can be arbitrarily removed without altering the proportion of infected fruit. Finally, while destructive sampling is more time-efficient and allows measurement of fruit weight, results indicate that fruit volume is just as good an independent variable for modeling. Thus, future research following the same cohort of fruit through time could effectively use fruit volume for growth measurements without any loss in accuracy.

\section{ACKNOWLEDGMENTS}

We thank P. V. Oudemans for his critical review of the manuscript and K. A. Foster and V. L. Roberts for their technical assistance. This research was funded in part by the New Jersey Agricultural Experiment Station.

\section{LITERATURE CITED}

1. Biggs, A. R., and Northover, J. 1988. Early and late-season susceptibility of peach fruits to Monilinia fructicola. Plant Dis. 72:10701074.

2. Blodgett, E. C. 1941. Rusty spot of peach. Plant Dis. Rep. 25:27-28.

3. Blodgett, E. C. 1941. Fruit diseases in Idaho. Plant Dis. Rep. 25:233-235.

4. Burchill, R. T. 1960. The role of secondary infections in the spread of apple mildew (Podosphaera leucotricha (Ell. and Ev.) Salm.). J. Hortic. Sci. 35:66-72.

5. Campbell, C. L., and Madden, L. V. 1990. Introduction to Plant Disease Epidemiology. John Wiley \& Sons, New York.

6. Daines, R. H., Haenseler, C. M., Brennan, E., and Leone, I. 1960. Rusty spot of peach and its control in New Jersey. Plant Dis. Rep. 44:20-22.

7. Daines, R. H., and Trout, J. R. 1977. Incidence of rusty spot of peach as influenced by proximity to apple trees. Plant Dis. Rep. 61:835-836.
8. DeJong, T. M., and Goudriaan, J. 1989. Modeling peach fruit growth and carbohydrate requirements: Reevaluation of the doublesigmoid pattern. J. Am. Soc. Hortic. Sci. 114:800-804

9. Flore, J. A. 1994. Stone fruit. Pages 233-270 in: Handbook of Environmental Physiology of Fruit Crops. Vol. I, Temperate Crops. B. Schaffer and P. C. Andersen, eds. CRC Press, Boca Raton, FL.

10. Furman, L. A., Lalancette, N., and White, J. F. 2001. Temporal analysis of peach rusty spot epidemics. (Abstr.) Phytopathology 91:S195.

11. Grove, G. G. 1995. Powdery mildew. Pages 12-14 in: Compendium of Stone Fruit Diseases. J. M. Ogawa, E. I. Zehr, G. W. Bird, D. F. Ritchie, K. Uriu, and J. K. Uyemoto, eds. American Phytopathological Society, St. Paul, $\mathrm{MN}$.

12. Grove, G. G. 1995. Rusty spot. Page 15 in: Compendium of Stone Fruit Diseases. J. M Ogawa, E. I. Zehr, G. W. Bird, D. F. Ritchie, K. Uriu, and J. K. Uyemoto, eds. American Phytopathological Society, St. Paul, MN.

13. Jeger, M. J. 1982. Using growth curve relative rates to model disease progress of apple powdery mildew. Prot. Ecol. 4:49-58.

14. Lalancette, N., and Hickey, K. D. 1986. Disease progression as a function of plant growth. Phytopathology 76:1171-1175.

15. Manji, B. T. 1972. Apple mildew on peach (Abstr.) Phytopathology 62:776.

16. Neher, D. A., and Campbell, C. L. 1992. Underestimation of disease progress rates with the logistic, monomolecular, and Gompertz models when maximum disease intensity is less than 100 percent. Phytopathology 82:811-814.

17. Polk, D., Schmitt, D., Rizio, E., and Peterson, K. 1997. The economic impact of peach pests in New Jersey 1996-1997. The New Jersey State Horticultural Society. Hortic. News 78(1):3-10.

18. Populer, C. 1978. Changes in host susceptibility with time. Pages 239-260 in: Plant Disease, An Advanced Treatise, Vol. II. How Disease Develops in Populations. J. G. Horsfall and E. B. Cowling, eds. Academic Press, New York.

19. Ries, S. M., and Royse, D. J. 1977. Rusty spot of peach in Illinois. Plant Dis. Rep. 61:317318.

20. Ries, S. M., and Royse, D. J. 1978. Peach rusty spot epidemiology: Incidence as affected by distance from a powdery-mildew infected apple orchard. Phytopathology 68:896899.

21. Sprague, R., and Figaro, P. 1956. Rusty spot, powdery mildew and healthy skin of peach fruits compared histologically. (Abstr.) Phytopathology 46:640.

22. Tukey, H. B. 1933. Growth of the peach embryo in relation to growth of fruit and season of ripening. Proc. Am. Soc. Hortic. Sci. 30:209-218.

23. Weinhold, A. R. 1961. The orchard development of peach powdery mildew. Phytopathology $51: 478-481$.

24. Westwood, M. N. 1993. Temperate Zone Pomology: Physiology and Culture. Timber Press, Portland, OR.

25. Zadoks, J. C., and Schein, R. D. 1979. Epidemiology and Plant Disease Management. Oxford University Press, New York. 